\title{
Effects of Cu coverage on the magnetic anisotropy of $\mathrm{Co} / \mathrm{Cu}(001)$
}

Article in Physical Review B · October 1999

DOI: $10.1103 /$ PhysRevB.60.9539

CITATIONS

14

2 authors:

\section{Vladimir Gavrilenko}

VLEXCO LLC

106 PUBLICATIONS $\quad \mathbf{1 , 2 4 8}$ CITATIONS

SEE PROFILE
READS

35

Some of the authors of this publication are also working on these related projects: 


\title{
Effects of $\mathrm{Cu}$ coverage on the magnetic anisotropy of $\mathrm{Co} / \mathrm{Cu}(001)$
}

\author{
V. I. Gavrilenko and Ruqian Wu \\ Department of Physics and Astronomy, California State University, Northridge, California 91330-8268
}

(Received 1 December 1998; revised manuscript received 26 April 1999)

\begin{abstract}
Using the full-potential linearized augmented plane wave method, the magnetocrystalline anisotropy (MCA) energies of the $\mathrm{Co} / \mathrm{Cu}(001), \mathrm{Cu} / \mathrm{Co} / \mathrm{Cu}(001)$, and $2 \mathrm{Cu} / \mathrm{Co} / \mathrm{Cu}(001)$ systems are investigated. With the generalized gradient approximation for the exchange-correlation energy/potential, the optimized atomic structures are remarkably improved from those obtained with the local-density approximation. The negative uniaxial MCA energy of $\mathrm{Co} / \mathrm{Cu}(001)(-0.61 \mathrm{meV}$ per $\mathrm{Co}$ adatom) changes to positive for $\mathrm{Cu} / \mathrm{Co} / \mathrm{Cu}(001)(0.54 \mathrm{meV}$ per $\mathrm{Co}$ adatom) and for $2 \mathrm{Cu} / \mathrm{Co} / \mathrm{Cu}(001)(0.21 \mathrm{meV}$ per Co adatom). This indicates that the $\mathrm{Cu}$ overlayers turn the magnetization of $\mathrm{Co}$ from the in-plane direction to the perpendicular axis, a conclusion which agrees with experiments. By contrast, the in-plane coefficient of MCA energy appears to be quite stable in these systems. [S0163-1829(99)03737-6]
\end{abstract}

\section{INTRODUCTION}

The determination of magnetocrystalline anisotropy (MCA) energies in various transition metal ultrathin films has attracted extensive attention in the last decade. ${ }^{1-6}$ Recent experiments found that magnetic anisotropy energy strongly depends on change in environment. For example, the inplane easy axis of $\mathrm{Co}$ films on $\mathrm{Cu}(001), \mathrm{Cu}(110)$, and $\mathrm{Cu}(111)$ can be turned to the perpendicular direction when they are capped by a few monolayers of nonmagnetic atoms such as $\mathrm{Cu}, \mathrm{Pd}, \mathrm{Ag}$, or $\mathrm{Au} .{ }^{2,3}$ Weber et al. reported that magnetic anisotropy of $\mathrm{Cu} / \mathrm{Co}$ thin films is strongly affected by the nonmagnetic vacuum/Cu interface even when it is displaced by as much as 16 atomic monolayer from the Co layers. ${ }^{5}$ Hope et al. found that a submonolayer $\mathrm{Cu}$ coverage can completely reverse the in-plane $90^{\circ}$ easy axis when depositing $\mathrm{Cu}$ overlayers onto the $\mathrm{Co}$ gas-dosed $\mathrm{Co} / \mathrm{Cu}(110)$ surface. ${ }^{6}$ By growing fcc $\mathrm{Co}$ films on a curved $\mathrm{Cu}(001)$ substrate, Kawakami et al. found that the magnetic anisotropy strength depend almost linearly on the step density. ${ }^{7}$

It is known that the magnetocrystalline anisotropy energy results mainly from spin-orbit coupling (SOC) interactions among the occupied and unoccupied states. Highly stable results of uniaxial MCA energies can be obtained now from the first-principles electronic structure calculations by treating the SOC Hamiltonian either self-consistently or perturbatively. ${ }^{8}$ By using the state-tracking ${ }^{9}$ and torque approaches ${ }^{10}$ based on the local-density full-potential linearized augmented plane wave (FLAPW) method, Zhong et al. and Kim et al. successfully reproduced and explained the effects of $\mathrm{Cu}$ coverage on the magnetic anisotropy behaviors of $\mathrm{Co} / \mathrm{Cu}(110)$ and $\mathrm{Co} / \mathrm{Cu}(111) .{ }^{11,12}$ Szunyogh et al., with the local-density screened Korringa-Kohn-Rostoker in atomic sphere approximation (SKKR-ASA) and the force theorem, studied the magnetic anisotropy energies of several $\mathrm{Co} / \mathrm{Cu}(001)$ systems capped by an additional monolayer of $\mathrm{Cu}, \mathrm{Ag}, \mathrm{Rh}, \mathrm{Au}$, or Pt. ${ }^{13}$ A large magnetostrictive coefficient is found $\left(\lambda_{001}\right.$ is $\left.-57 \times 10^{-6}\right)$ at the $\mathrm{Co} / \mathrm{Cu}(001)$ interface in previous calculations, ${ }^{14,15}$ which indicates that the MCA energy strongly depends on the interfacial structural relaxation.

Due to the known deficiency of the local-density approxi- mation ( $\mathrm{LDA}$ ), the $\mathrm{Co} / \mathrm{Cu}$ interlayer distances in all previous calculations were underestimated by several percents. ${ }^{11,14,15}$ This certainly makes the calculated MCA energies questionable with geometries optimized through LDA calculations. In addition, since the MCA energy is very sensitive to small changes in the band structure near the Fermi level, it is important to investigate effects of the charge- and spin-density corrugations.

In this paper, we report results of structural, electronic, and magnetic properties of $\mathrm{Co} / \mathrm{Cu}(001), \mathrm{Cu} / \mathrm{Co} / \mathrm{Cu}(001)$, and $2 \mathrm{Cu} / \mathrm{Co} / \mathrm{Cu}(001)$, using the generalized gradient approximation (GGA). ${ }^{16}$ The $\mathrm{Co} / \mathrm{Cu}$ and $\mathrm{Cu} / \mathrm{Cu}$ interlayer distances are found to be significantly larger than the corresponding LDA results. The calculated uniaxial MCA energies are $-0.61 \mathrm{meV},+0.54 \mathrm{meV}$, and $+0.21 \mathrm{meV}$ for $\mathrm{Co} / \mathrm{Cu}(001)$, $\mathrm{Cu} / \mathrm{Co} / \mathrm{Cu}(001)$, and $2 \mathrm{Cu} / \mathrm{Co} / \mathrm{Cu}(001)$, respectively. Reliable results are also obtained for the in-plane MCA coefficients.

\section{METHOD}

The FLAPW method ${ }^{17}$ solves the single-particle KohnSham equations self-consistently, with a fully relativistic treatment for both core and valence states. To simplify the calculations, the SOC Hamiltonian $\left(H_{S O C}=\xi \mathbf{s} \cdot \mathbf{L}\right)$ for the valence states is invoked second-variationally, with $z$-spin magnetization. Since the strength of $H_{S O C}$ is much weaker than that of the crystal-field interaction in $3 d$-transition-metal systems, we neglected the spin-flipping effect and projected the wave functions, charge densities, and potentials to two separate spin channels as done in semirelativistic calculations. $^{8}$

No shape approximation is assumed for charge, potential, and wave functions. The GGA formula of Ref. 16 is adopted to describe the exchange-correlation effects. In the muffin-tin region, spherical harmonics with a maximum angular momentum of eight are used to expand the charge, potential, and wave functions. In the interstitial area, plane waves with energy cutoffs of 150 Ry (for the charge and potential) and 14 Ry (for the variational bases) are employed. Selfconsistency is assumed when the root-mean-square distances between the input and output charge and spin densities be- 
come less than $1.0 \times 10^{-4}$ electrons/a.u. ${ }^{3} 300 \mathbf{k}$ points in the $1 / 8$ irreducible part of the two-dimensional Brillouin zone are used for integrals in the reciprocal space.

The $\mathrm{Cu}(001)$ substrate is modeled by a five-layer $\mathrm{Cu}(001)$ slab. We studied (1) the clean $\mathrm{Co} / \mathrm{Cu}(001)$ surface, (2) the $\mathrm{Cu} / \mathrm{Co} / \mathrm{Cu}(001)$, and (3) the $2 \mathrm{Cu} / \mathrm{Co} / \mathrm{Cu}(001)$ systems to investigate the effects of the $\mathrm{Cu}$ cap layers. $\mathrm{Co}$ and $\mathrm{Cu}$ adatoms are placed pseudomorphically on both sides of the slab to retain the inversion symmetry. The equilibrium atomic structures are determined through total energy and atomic force calculations, with a criterion that requires the force on each atom to be smaller than $2 \times 10^{-3}$ Hartree/a.u.

For a system with fourfold symmetry with respect to its surface normal, the magnetocrystalline anisotropy energy, $E_{M C A}$, can be expressed in the lowest nonvanishing order of the polar and azimuth angles ( $\theta$ and $\phi$, respectively) as ${ }^{2,18}$

$$
E_{M C A}=K_{1} \sin ^{2} \theta+K_{2} \sin ^{2}(2 \phi) \sin ^{4} \theta .
$$

Here $K_{1}$ and $K_{2}$ are the coefficients of the leading uniaxial and in-plane contributions to $E_{M C A}$, respectively. They can be determined through angular derivatives of $E_{M C A}(T$ $=d E_{M C A} / d \theta$, where $T$ is the torque) as

$$
K_{1}=T\left(\theta=45^{\circ}, \phi=0^{\circ}\right), \quad K_{2}=T\left(\theta=45^{\circ}, \phi=45^{\circ}\right)-K_{1} .
$$

Here, $T$ is calculated through the expectation value of the angular derivative of $H_{S O C}$ as

$$
T(\theta, \phi)=\sum_{i \in \mathrm{occ}}\left\langle i\left|\frac{\partial H_{S O C}(\theta, \phi)}{\partial \theta}\right| i\right\rangle
$$

and

$$
H_{S O C}=\left(\begin{array}{ll}
H_{S O C}^{\uparrow \uparrow} & H_{S O C}^{\uparrow \downarrow} \\
H_{S O C}^{\downarrow \uparrow} & H_{S O C}^{\downarrow \downarrow}
\end{array}\right)
$$

Here $\quad H_{S O C}^{\uparrow \uparrow}=\cos \theta L_{z}+\sin \theta(A+B) / 2 ; \quad H_{S O C}^{\downarrow \downarrow}=-\cos \theta L_{z}$ $-\sin \theta(A+B) / 2 ; \quad H_{S O C}^{\uparrow \downarrow}=\cos ^{2}(\theta / 2) A-\sin ^{2}(\theta / 2) B-\sin \theta L_{z} ;$ and $\quad H_{S O C}^{\downarrow \uparrow}=\cos ^{2}(\theta / 2) B-\sin ^{2}(\theta / 2) A-\sin \theta L_{z} \quad$ (with $A$ $=e^{i \phi} L_{-}$and $\left.B=e^{-i \phi} L_{+}\right)$. The spin-flipping terms (i.e., $H_{S O C}^{\downarrow \uparrow}$ and $H_{S O C}^{\uparrow \downarrow}$ ), do not affect charge density much but may contribute significantly to the MCA energy. ${ }^{8}$

$K_{1}$ can be determined quite satisfactorily for most magnetic thin films through the first-principles calculations using torque, force theorem, or total-energy approaches. ${ }^{8}$ By contrast, $K_{2}$ is very small (a few $\mu \mathrm{eV} /$ atom) and thus is very difficult for force theorem and total-energy approaches.

\section{ATOMIC STRUCTURE AND MAGNETISM}

To demonstrate the advantages of the GGA approach for structural optimizations, we first calculated the fcc bulk $\mathrm{Cu}$ using both GGA and LDA density-functional formulas. The calculated ratios of theoretical and experimental lattice constants $\left(r=a_{\text {theo }} / a_{\text {exp }}\right.$, with $a_{\text {exp }}=6.83$ a.u.) are 1.004 with GGA and 0.975 with LDA, respectively. Clearly, the GGA result $(0.4 \%$ larger $)$ is much better than the LDA counterpart ( $2.5 \%$ smaller) compared to the experimental data. Our test calculations indicated that GGA systematically improves the reliability of the calculated lattice constants, cohesion energies, and bulk moduli for all $3 d$ transition metals. ${ }^{19}$ For ex-
TABLE I. The calculated equilibrium vertical positions $(z$, in a.u.) spin $(M)$, and orbital $\left(L_{z}\right)$ magnetic moments (in $\mu_{B}$ ) of the $\mathrm{Cu} / \mathrm{Co} / \mathrm{Cu}(001)$ systems.

\begin{tabular}{lcccccc}
\hline \hline & $\mathrm{Cu}(1)$ & $\mathrm{Cu}(2)$ & $\mathrm{Cu}(3)$ & $\mathrm{Co}$ & $\mathrm{Cu}(4)$ & $\mathrm{Cu}(5)$ \\
\hline $\mathrm{Co} / \mathrm{Cu}_{5}$ & & & & & & \\
$z$ & 0.0 & 3.47 & 6.98 & 10.43 & & \\
$M$ & -0.001 & -0.01 & 0.017 & 1.92 & & \\
$L_{z}$ & 0.00 & -0.004 & 0.002 & 0.118 & & \\
& & & & & & \\
$\mathrm{Cu} / \mathrm{Co} / \mathrm{Cu}_{5}$ & & & & & & \\
$z$ & 0.0 & 3.48 & 7.00 & 10.50 & 13.93 & \\
$M$ & 0.002 & -0.007 & 0.02 & 1.74 & 0.025 & \\
$L_{z}$ & 0.00 & -0.005 & 0.001 & 0.117 & 0.002 & \\
& & & & & & \\
$\mathrm{Cu} / \mathrm{Co} / \mathrm{Cu}_{5}$ & & & & & & \\
$z$ & 0.0 & 3.48 & 7.00 & 10.49 & 13.95 & 17.45 \\
$M$ & 0.001 & -0.008 & 0.02 & 1.74 & 0.037 & -0.004 \\
$L_{z}$ & 0.00 & -0.002 & 0.001 & 0.099 & 0.002 & 0.00 \\
\hline \hline
\end{tabular}

ample, the calculated bulk modulus $(B)$ for the bulk fcc $\mathrm{Cu}$ with GGA, $B_{G G A}$, is $132.7 \mathrm{GPa}$, a value that agrees excellently with experiment for fcc bulk $\mathrm{Cu}, 134.3 \mathrm{GPa}^{20} \mathrm{By}$ contrast, the bulk modulus calculated using LDA for the fcc bulk $\mathrm{Cu}$ is $161.7 \mathrm{GPa}$, which is obviously much too large.

For all the thin films, we used an in-plane lattice constant, 4.83 a.u. (corresponding to $a=6.83$ a.u. in the cubic fcc cell). The vertical positions of all the atoms in the unit cell were adjusted according to their atomic forces. The calculated equilibrium $z$ coordinates are presented in Table I. As expected, the $\mathrm{Cu} / \mathrm{Cu}$ interlayer distance in the interior region remains constant, 3.47-3.48 a.u., in all the systems studied. This value is slightly larger than the measured value, 3.42 a.u., since the GGA-optimized lattice constant for bulk $\mathrm{Cu}$ (6.86 a.u.) is $0.4 \%$ larger than that used in the lateral plane. $\mathrm{By}$ contrast, the average $\mathrm{Cu}-\mathrm{Cu}$ interlayer distance from LDA calculations is $3.25-3.32$ a.u. for $\mathrm{Co} / \mathrm{Cu}(001) .{ }^{14}$ Clearly, GGA is more suitable than LDA to optimize that atomic structure of magnetic thin films.

The $\mathrm{Cu}-\mathrm{Cu}$ interlayer distance at the interfacial region appears to be $1 \%$ larger than that in the interior region $(3.51$ a.u. versus 3.47 a.u.). This indicates that Co induces a slight lattice expansion in the adjacent $\mathrm{Cu}$ layers. Here, the surface $\mathrm{Co}-\mathrm{Cu}$ interlayer distances in $\mathrm{Co} / \mathrm{Cu}(001)$ and $\mathrm{Cu} / \mathrm{Co} /$ $\mathrm{Cu}(001)$ are 3.43-3.45 a.u. This value is about $10 \%$ larger than that obtained in previous LDA calculations, 3.08-3.11 a.u. ${ }^{14,15}$ Interestingly, the surface $\mathrm{Cu}-\mathrm{Cu}$ interlayer distance 3.50 a.u. expands by $1 \%$ from that in the interior region. This result agrees excellently with a low-energy electrondiffraction (LEED) experiment that found a slight expansion $(1.5 \%)$ at the $\mathrm{Cu}(001)$ clean surface. ${ }^{21}$

In Figs. 1-3, the calculated valence charge and spin densities of $\mathrm{Co} / \mathrm{Cu}(001), \mathrm{Cu} / \mathrm{Co} / \mathrm{Cu}(001)$, and $2 \mathrm{Cu} / \mathrm{Co} / \mathrm{Cu}(001)$ are presented, respectively. Strong $\mathrm{Co} / \mathrm{Cu}$ interfacial interaction can be seen from the charge-density contours around the $\mathrm{Co}$ atoms. The profile of contours in the region below the $\mathrm{Co}$ plane in $\mathrm{Co} / \mathrm{Cu}(001)$ is already very similar to that around the interior $\mathrm{Cu}$ atoms. Directional bonds are shown between $\mathrm{Cu}(4)-\mathrm{Co}$ atoms in both $\mathrm{Cu} / \mathrm{Co} / \mathrm{Cu}(001)$ and $2 \mathrm{Cu} / \mathrm{Co} /$ $\mathrm{Cu}(001)$ systems. From the spin-density contours, the $\mathrm{Cu}-\mathrm{Co}$ 


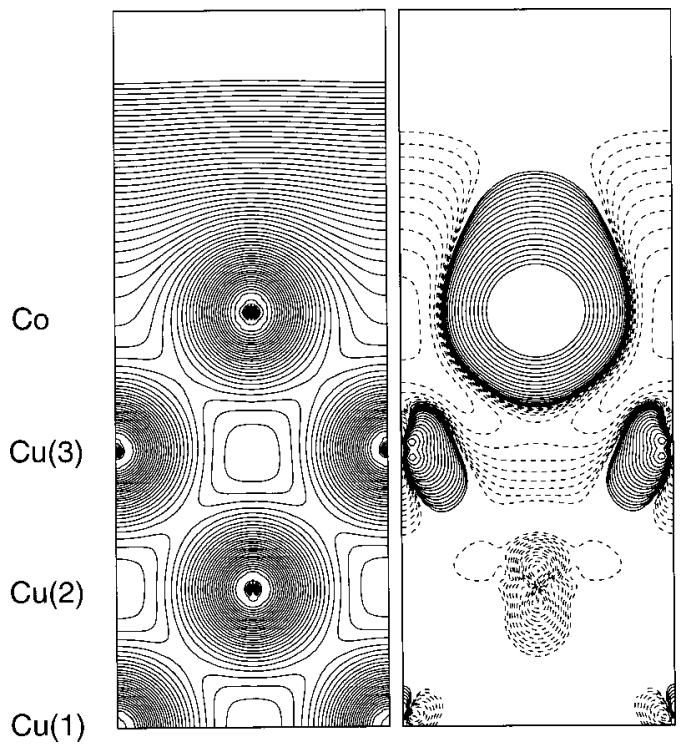

FIG. 1. The calculated valence charge (a) and spin (b) densities of $\mathrm{Co} / \mathrm{Cu}(001)$. Contours start from $\pm 1 \times 10^{-3} e /$ a.u. ${ }^{3}$, and increase successively by a factor of $\sqrt{2}$. Solid and dashed contours in panel (b) denote positive and negative spin densities, respectively.

hybridization can be found to be detrimental to the spin polarization of the Co atom. The area of positive spin density (solid contours) on top of the $\mathrm{Co}$ atom in $\mathrm{Co} / \mathrm{Cu}(001)$ is significantly depressed by the $\mathrm{Cu}$ coverage, especially in $\mathrm{Cu} /$ $\mathrm{Co} / \mathrm{Cu}(001)$. The induced spin density in the $\mathrm{Cu}$ layers change quickly from the $d$-like to $s p$-like away from the interfacial region. Quantitatively, the calculated spin (orbital) magnetic moments of the Co atom are $1.92(0.118) \mu_{B}$, $1.74(0.117) \mu_{B}$, and $1.74(0.099) \mu_{B}$ in $\mathrm{Co} / \mathrm{Cu}(001), \mathrm{Cu} /$ $\mathrm{Co} / \mathrm{Cu}(001)$, and $2 \mathrm{Cu} / \mathrm{Co} / \mathrm{Cu}(001)$, respectively. The orbital magnetic moments calculated here, with contributions from the SOC only, are somewhat smaller than the measured value $\left(0.18 \mu_{B}\right)$ using the $\mathrm{x}$-ray magnetic circular dichroism sum rules. ${ }^{22}$

Curves of the calculated density of states (DOS) shown in Figs. 4-6 indicate more clearly the interfacial hybridization

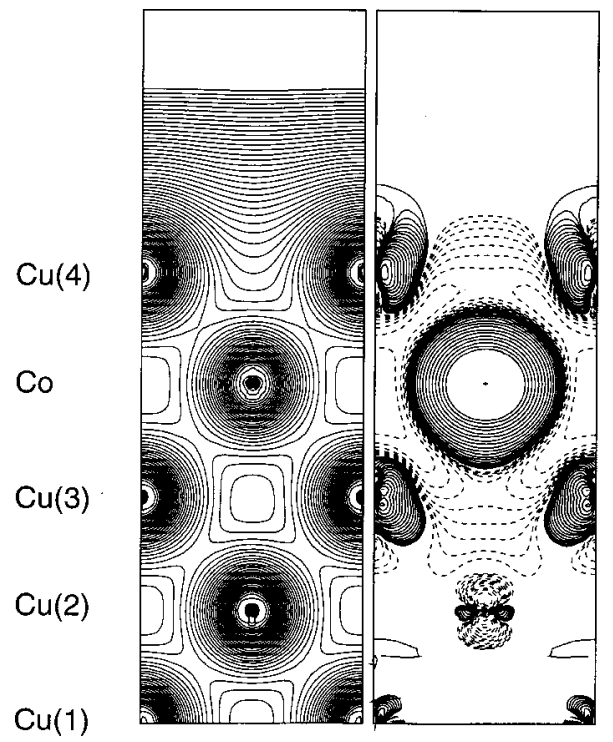

FIG. 2. As in Fig. 1, but for $\mathrm{Cu} / \mathrm{Co} / \mathrm{Cu}(001)$.

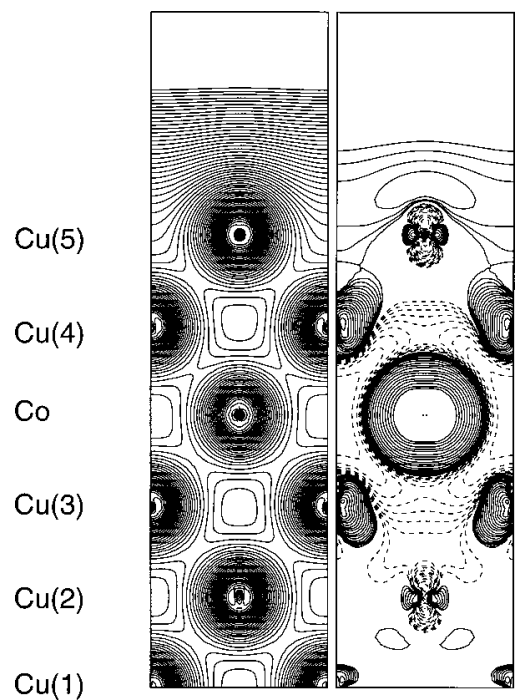

FIG. 3. As in Fig. 1, but for $2 \mathrm{Cu} / \mathrm{Co} / \mathrm{Cu}(001)$.

between the $\mathrm{Cu}$ and $\mathrm{Co}$ atoms. For the majority-spin part, the $\mathrm{Co} d$ band overlaps with that of $\mathrm{Cu}$ in energy and thus $\mathrm{Co}-\mathrm{Cu}$ interaction is very similar to $\mathrm{Cu}-\mathrm{Cu}$ interaction. For the minority-spin part, $\mathrm{Cu}$ and $\mathrm{Co} d$ states hybridize mainly in the occupied region. The Co $d$ band in $\mathrm{Cu} / \mathrm{Co} / \mathrm{Cu}(001)$ is significantly broadened from that in $\mathrm{Co} / \mathrm{Cu}(001)$. Even the DOS of $\mathrm{Cu}(3)$ is noticeably affected. From $\mathrm{Cu} / \mathrm{Co} / \mathrm{Cu}(001)$ to $2 \mathrm{Cu} / \mathrm{Co} / \mathrm{Cu}(001)$, the $\mathrm{Co}-\mathrm{Cu}(4)$ hybridization appears to be weakened by the additional $\mathrm{Cu}(5)$ overlayer, which broadens and shifts the $\mathrm{Cu}(4) d$ band to the low-energy region.

\section{MAGNETOCRYSTALLINE ANISOTROPY}

In Fig. 7, the calculated values of both $K_{1}$ and $K_{2}$ coefficients for $\mathrm{Co} / \mathrm{Cu}(001), \mathrm{Cu} / \mathrm{Co} / \mathrm{Cu}(001)$, and $2 \mathrm{Cu} / \mathrm{Co} / \mathrm{Cu}(001)$ are given versus their numbers of valence electrons (obtained by varying the position of the highest-occupied energy level

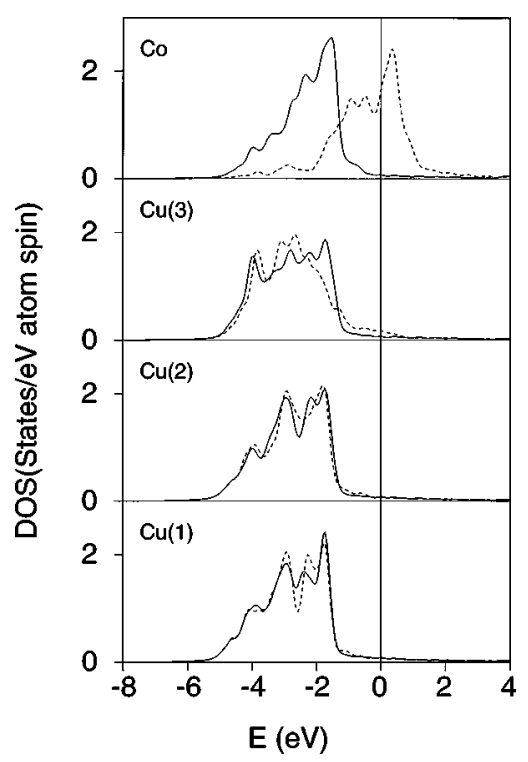

FIG. 4. The calculated density of states for each atom of $\mathrm{Co} /$ $\mathrm{Cu}(001)$. Solid and dashed lines represent majority and minority spin parts, respectively. Zero on the energy scale represents the Fermi energy. 


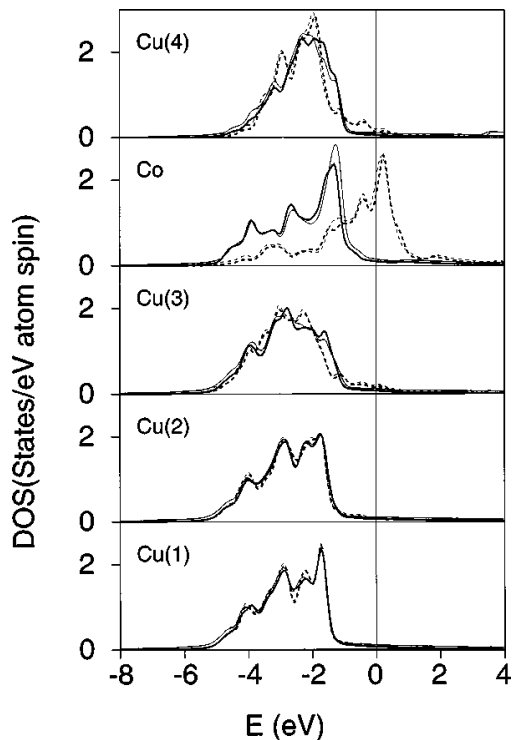

FIG. 5. As in Fig. 4, but for $\mathrm{Cu} / \mathrm{Co} / \mathrm{Cu}(001)$. Thin lines indicate the LDA results.

for each system). For all the systems, both $K_{1}$ and $K_{2}$ curves are quite smooth-indicating the numerical stability of the present results of MCA energy determined through the FLAPW method. Test calculations indicated that $K_{1}\left(K_{2}\right)$ is converged to better than $0.05 \mathrm{meV}(3 \mu \mathrm{eV})$ with $300 k$ points in the 1/8 irreducible two-dimensional Brillouin zone.

As was discussed by Zhong et al. for $\mathrm{Co} / \mathrm{Cu}(111),{ }^{11}$ the calculated results of $K_{1}$ change drastically, from $-0.61 \mathrm{meV}$ per $\mathrm{Co}$ atom for $\mathrm{Co} / \mathrm{Cu}(001)$ to $+0.54 \mathrm{meV}$ per Co atom in $\mathrm{Cu} / \mathrm{Co} / \mathrm{Cu}(001)$ and, finally, to $0.21 \mathrm{meV}$ per $\mathrm{Co}$ atom in $2 \mathrm{Cu} / \mathrm{Co} / \mathrm{Cu}(001)$. These results explain previous experimental observation by Krams et al. ${ }^{2}$ for $\mathrm{Cu} / \mathrm{Co} / \mathrm{Cu}(001)$ and Engel et $\mathrm{al}^{3}{ }^{3}$ for Co films in other structures, that the nonmagnetic $\mathrm{Cu}$ coverage alters the Co magnetization from the lateral plane to the perpendicular axis.

The mechanism of this "anomalous perpendicular anisotropy" was discussed by several authors for different

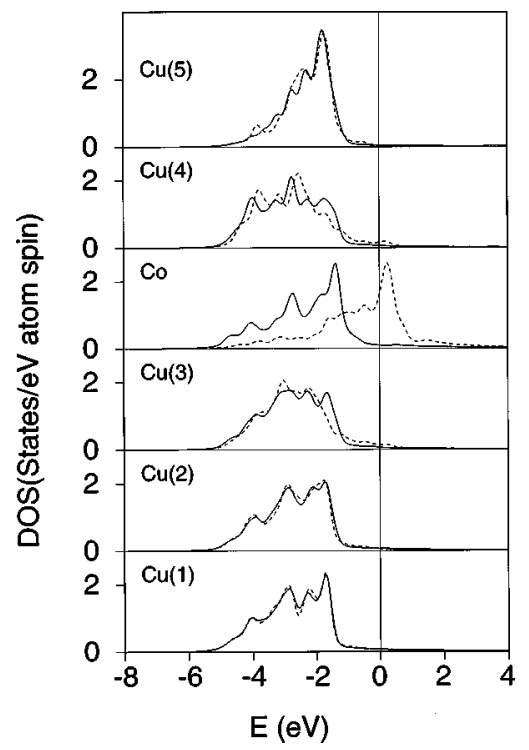

FIG. 6. As in Fig. 4, but for $2 \mathrm{Cu} / \mathrm{Co} / \mathrm{Cu}(001)$.
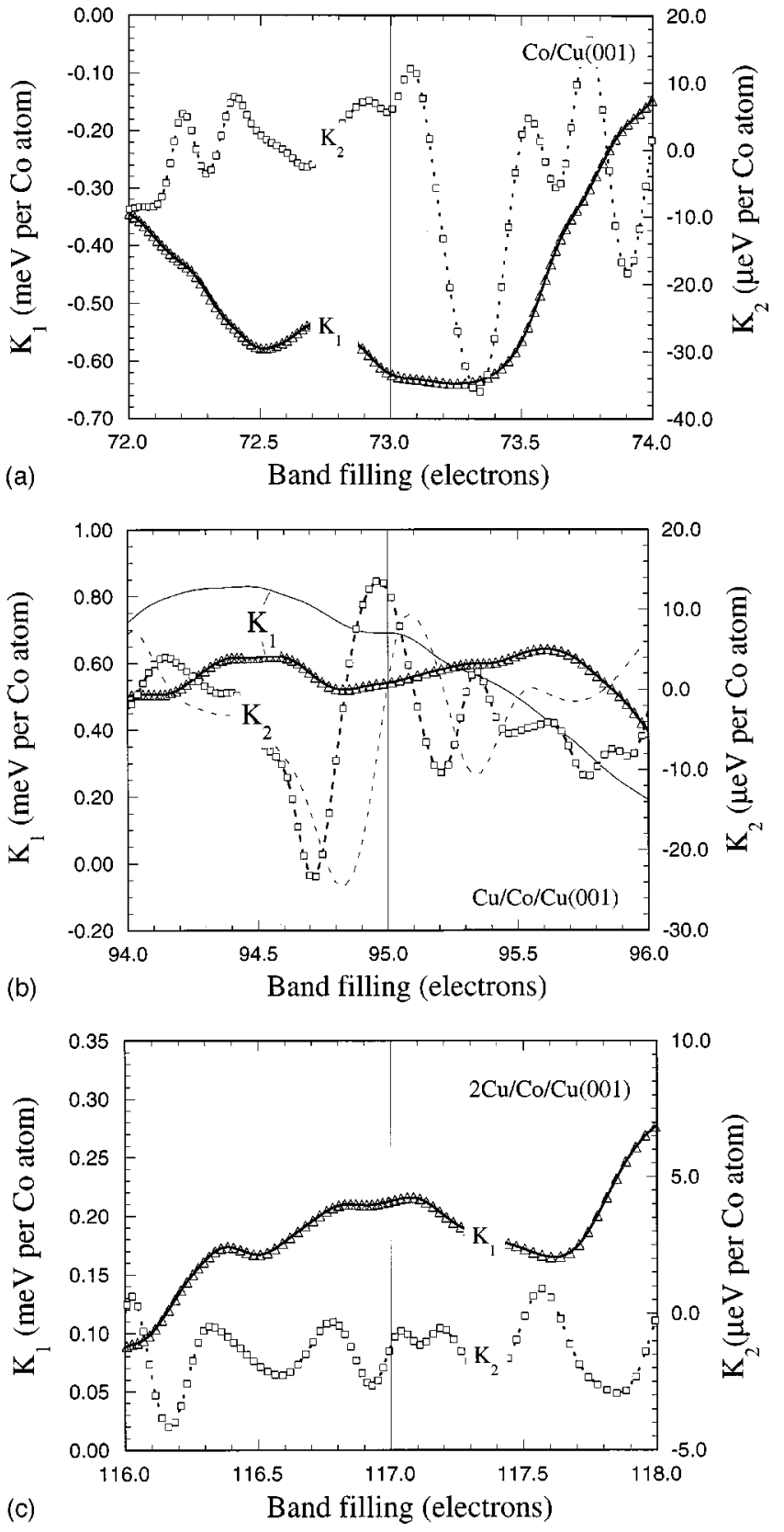

FIG. 7. The calculated MCA energy coefficients for (a) $\mathrm{Co} /$ $\mathrm{Cu}(001),(\mathrm{b}) \mathrm{Cu} / \mathrm{Co} / \mathrm{Cu}(001)$, and (c) $2 \mathrm{Cu} / \mathrm{Co} / \mathrm{Cu}(001)$ versus band filling. Thin lines in panel (b) stand for LDA results using the equilibrium atomic structure optimized through GGA calculations.

systems. ${ }^{11,13}$ For $\mathrm{Cu} / \mathrm{Co} / \mathrm{Cu}(001)$, we can start from why $\mathrm{Co}(001)$ film has a negative $E_{M C A}$ (i.e., in-plane magnetic anisotropy). From band structure analyses for a free $\mathrm{Co}(001)$ monolayer, we pointed out that this was mainly due to the SOC interaction between the occupied $d_{x z, y z}$ states ( $m=$ \pm 1 , where $m$ represents the magnetic quantum number) and the unoccupied $d_{z^{2}}(m=0)$ and $d_{x y}(m= \pm 2)$ states at the $\bar{M}$ point in the minority-spin channel. This interaction is drastically weakened when the Co thin film is deposited on the $\mathrm{Cu}(001)$ substrate or sandwiched by $\mathrm{Cu}$ cap layers. As discussed above, the $\mathrm{Cu} d$ states are far below the Fermi level and thus only affect the Co $d_{x z, y z}$ states with minority spin. Effectively, Co-Cu hybridization drags down the Co $d_{x z, y z}$ states and enlarges the energy separations between the Co $d_{x z, y z}$ states and the unoccupied Co $d$ states. As a result, 

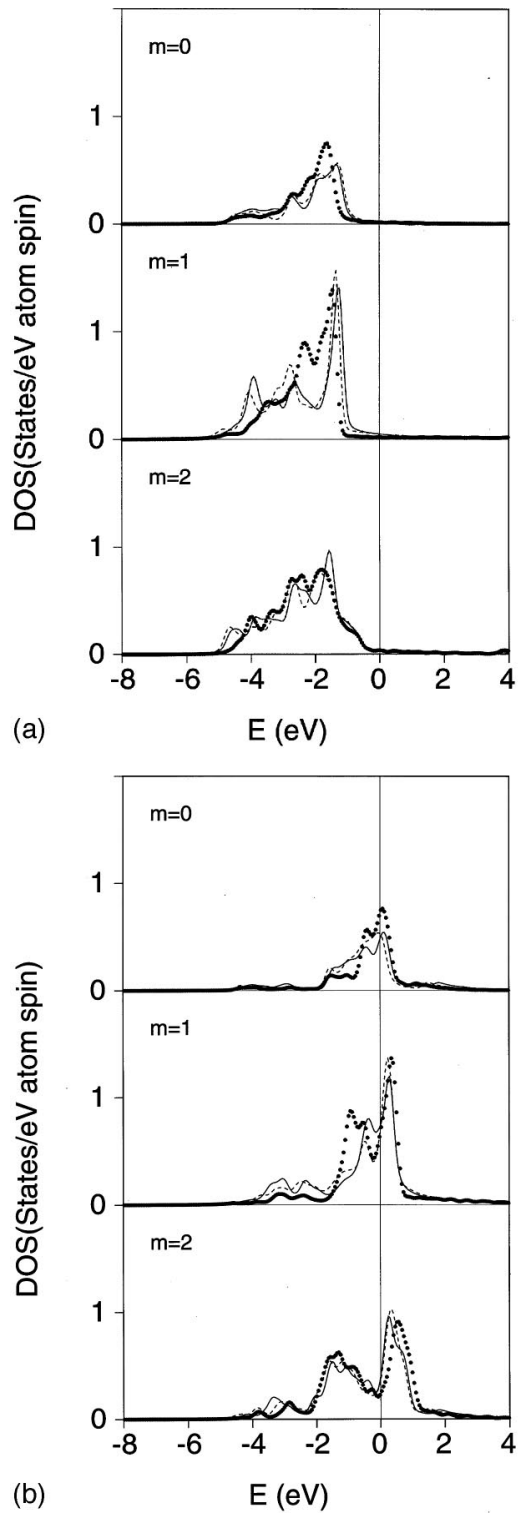

FIG. 8. The $m$-projected density of states for the Co $d$ bands in $\mathrm{Co} / \mathrm{Cu}(001)$ (dotted lines), $\mathrm{Cu} / \mathrm{Co} / \mathrm{Cu}(001)$ (solid lines), and $2 \mathrm{Cu} /$ $\mathrm{Co} / \mathrm{Cu}(001)$ (dashed lines). The majority- and minority-spin parts are given in panels (a) and (b), respectively.

the negative contributions to $E_{M C A}$ are reduced. Meanwhile, the positive contributions to $E_{M C A}$ are mainly from the inplane Co $d_{x y}$ and $d_{x^{2}-y^{2}}$ states, and thus are quite insensitive to the presence of $\mathrm{Cu}$ neighbors and finally prevail the negative contributions in $\mathrm{Cu} / \mathrm{Cu} / \mathrm{Cu}(001)$.

This mechanism is clearly shown in Fig. 8 by the $m$-projected density of states in the Co muffin-tin sphere. Since the $\mathrm{Cu}$ states are far below the Fermi level, they mainly hybridize with the occupied Co states. As expected, the DOS curve for the Co $d_{x z}$ and $d_{y z}$ states $(m=1)$ is strongly affected by the surrounding $\mathrm{Cu}$ layers. The peak at $-1.2 \mathrm{eV}$ in $\mathrm{Co} / \mathrm{Cu}(001)$ of the minority spin Co $d$ band [cf. Fig. 8(b)] is split into three peaks at $-0.6 \mathrm{eV},-2.2 \mathrm{eV}$, and $-3.0 \mathrm{eV}$ in the $\mathrm{Cu} / \mathrm{Co} / \mathrm{Cu}(001)$ and $2 \mathrm{Cu} / \mathrm{Co} / \mathrm{Cu}(001)$ systems, respectively. Meanwhile, the minority spin $\operatorname{Co} d_{z^{2}}$ surface state in $\mathrm{Co} / \mathrm{Cu}(001)$ gains some electrons and shift to the low-energy region. The SOC interaction between the minority-spin Co $d_{z^{2}}$ and Co $d_{x z, y z}$ states (through the $L_{x}$ operator) is reduced whereas that between the minority spin Co $d_{x z}$ and Co $d_{y z}$ states (through the $L_{z}$ operator) is enhanced. This thus results in a positive MCA energy. The second $\mathrm{Cu}$ overlayer, however, weakens this effect since the $m$-projected DOS curves of $2 \mathrm{Cu} / \mathrm{Co} / \mathrm{Cu}(001)$ are always between those of $\mathrm{Co} / \mathrm{Cu}(001)$ and $\mathrm{Cu} / \mathrm{Co} / \mathrm{Cu}(001)$.

The calculated values of $K_{2}$ are positive for $\mathrm{Co} / \mathrm{Cu}(001)$ $(6 \mu \mathrm{eV})$ and $\mathrm{Cu} / \mathrm{Co} / \mathrm{Cu}(001)(11 \mu \mathrm{eV})$, which indicates that the easy axis is along the (110) direction in the cubic unit cell. In $2 \mathrm{Cu} / \mathrm{Co} / \mathrm{Cu}(001), K_{2}$ changes to negative $(-1 \mu \mathrm{eV})$. This means that the in-plane MCA energy is very sensitive to the environment even in the second neighbors. Experimentally, Krams et al. ${ }^{2}$ found that the $K_{2}$ coefficient is almost independent of the $\mathrm{Cu}$ coverage. By contrast, more recent experiments by Weber and Hope et al. ${ }^{5,6}$ observed significant changes in $K_{2}$ with the $\mathrm{Cu}$ coverage, even when it is as thick as $16 \mathrm{ML}$.

By comparing LDA and GGA results, we found that the gradient corrections affect the MCA energy strongly. Using the same atomic structures, LDA produces uniaxial MCA energies of $-0.36 \mathrm{meV}$ and $+0.69 \mathrm{meV}$ for $\mathrm{Co} / \mathrm{Cu}(001)$ and $\mathrm{Cu} / \mathrm{Co} / \mathrm{Cu}(001)$, respectively. With the LDA-optimized structure, the value of $K_{1}$ for $\mathrm{Co} / \mathrm{Cu}(001)$ is only $-0.12 \mathrm{meV}^{14}$

From the LDA and GGA DOS curves for $\mathrm{Cu} / \mathrm{Co} / \mathrm{Cu}(001)$ in Fig. 5, the gradient corrections appear not to change the band structure much, especially for the $\mathrm{Cu}$ atoms. For $\mathrm{Co}$, GGA slightly enhances the exchange splitting (by $0.1-0.2$ $\mathrm{eV}$ ) and weakens the $\mathrm{Co} / \mathrm{Cu}$ interfacial interaction (cf. the reduction for the peaks at $-0.6 \mathrm{eV},-1.3 \mathrm{eV}$, and $-3.2 \mathrm{eV}$ in the minority-spin DOS curves). By contrast, the calculated values of $K_{1}$ and $K_{2}$ for $\mathrm{Cu} / \mathrm{Co} / \mathrm{Cu}(001)$ in Fig. 7(b) appear to be very sensitive to the gradient corrections. Using the same atomic structure optimized through GGA calculations, LDA results of $K_{1}$ and $K_{2}$ curves deviate markedly from the GGA counterparts. Although the trends of $K_{2}$ curves appear to be very similar, LDA gives a very small in-plane anisotropy energy (1.2 $\mu \mathrm{eV}$ per Co atom). This is understandable since MCA energies mainly depend on the Co $d$ states near the Fermi level. In our recent calculations, we also found significant discrepancies between LDA and GGA results of MCA energies in the free $\mathrm{Ni}$ and $\mathrm{Fe}$ monolayers. $^{8}$

Clearly, the gradient corrections in GGA not only improve the results of structural optimizations for $3 d$-transition metals, but alter their band structures also. Both effects have significant consequences for the determination of MCA energies. Comparing to the measured uniaxial $E_{M C A}$ available for $\mathrm{Co} / \mathrm{Cu}(001), 0.38 \mathrm{meV}$ per $\mathrm{Co}$ atom, ${ }^{2}$ it appears that LDA produces a better agreement. However, one must view this agreement very cautiously since this value was extrapolated from data for samples with thicker Co layers. Further experimental measurements for $E_{M C A}$ of the $\mathrm{Co} / \mathrm{Cu}(001)$ systems in the monolayer regime are desired.

\section{CONCLUSIONS}

The FLAPW method with GGA is applied for the determination of structural, electronic, and magnetic properties of $\mathrm{Co} / \mathrm{Cu}(001)$ systems with $\mathrm{Cu}$ cap layers. The GGA is found to improve the reliability of first-principles structure optimizations for $3 d$ metals and to strongly alter results of MCA 
energies. The calculated uniaxial MCA energies are $-0.61 \mathrm{meV},+0.54 \mathrm{meV}$, and $+0.21 \mathrm{meV}$ for $\mathrm{Co} / \mathrm{Cu}(001)$, $\mathrm{Cu} / \mathrm{Co} / \mathrm{Cu}(001)$, and $2 \mathrm{Cu} / \mathrm{Co} / \mathrm{Cu}(001)$, respectively. This explains the "anomalous perpendicular anisotropy" observed in $\mathrm{Co} / \mathrm{Cu}$ and other systems.

\section{ACKNOWLEDGMENTS}

This work was supported by the Office of Naval Research (Grant No. N0014-95-1-0489), and by computing grants at ARSC and NAVO through the ONR.

${ }^{1}$ P. A. Gacia, A. D. Meinholdt, and A. Suna, Appl. Phys. Lett. 47, 178 (1985).

${ }^{2}$ P. Krams, F. Lauks, R. L. Stamps, B. Hillebrands, and G. Güntherodt, Phys. Rev. Lett. 69, 3674 (1992).

${ }^{3}$ B. N. Engel, M. H. Wiedmann, and C. M. Falco, J. Appl. Phys. 75, 6401 (1994).

${ }^{4}$ F. Huang, G. J. Mankey, and R. J. Willis, J. Appl. Phys. 75, 6406 (1994).

${ }^{5}$ W. Weber, A. Bischof, R. Allenspach, C. H. Back, J. Fassbender, U. May, B. Schirmer, R. M. Jungblut, G. Güntherodt, and B. Hillebrandt, Phys. Rev. B 54, 4075 (1996).

${ }^{6}$ S. Hope, E. Gu, B. Choi, and J. A. Bland, Phys. Rev. Lett. 80, 1750 (1998).

${ }^{7}$ R. K. Kawakami, M. O. Bowen, H. J. Choi, E. J. EscorcisAparicio, and Z. Q. Qiu, Phys. Rev. B 58, R5924 (1998).

${ }^{8}$ R. Q. Wu and A. J. Freeman, J. Magn. Magn. Mater. (to be published).

${ }^{9}$ D.-S. Wang, R. Q. Wu, and A. J. Freeman, Phys. Rev. Lett. 70, 869 (1993).

${ }^{10}$ X. Wang, R. Wu, D.-S. Wang, and A. J. Freeman, Phys. Rev. B 54, 61 (1996).

${ }^{11}$ L. Zhong, M. Kim, X. Wang, and A. J. Freeman, Phys. Rev. B 53, 9770 (1996).

${ }^{12}$ M. Kim, L. Zhong, and A. J. Freeman, Phys. Rev. B 57, 5271 (1998).

${ }^{13}$ L. Szunyogh, B. Ujfalussy, U. Pustogowa, and P. Weinberger, Phys. Rev. B 57, 8838 (1998).

${ }^{14}$ R. Q. Wu and A. J. Freeman, J. Appl. Phys. 79, 6500 (1996); R. Q. Wu, L. J. Chen, and A. J. Freeman, J. Magn. Magn. Mater. 170, 103 (1997).

${ }^{15}$ A. B. Shick, D. L. Novikov, and A. J. Freeman, Phys. Rev. B 56, R14 259 (1997).

${ }^{16}$ J. P. Perdew, K. Burke, and Y. Wang, Phys. Rev. B 54, 16533 (1996).

${ }^{17}$ E. Wimmer, H. Krakauer, M. Weinert, and A. J. Freeman, Phys. Rev. B 24, 864 (1981), and references therein.

${ }^{18}$ J. A. C. Bland, G. A. Gehrig, B. Kaplan, and C. Daboo, J. Magn. Magn. Mater. 113, 173 (1992).

${ }^{19}$ R. Q. Wu, L. J. Chen, A. B. Shick, and A. J. Freeman, J. Magn. Magn. Mater. 177, 1216 (1998).

${ }^{20}$ T. Soma, Physica B \& C 97, 76 (1979).

${ }^{21}$ J. Stohr, R. Jaeger, and T. Kendelewicz, Phys. Rev. Lett. 49, 142 (1982).

${ }^{22}$ M. Tischer, O. Hjortstam, D. Arvanitis, J. H. Dunn, F. May, K. Baberschke, J. Trygg, J. M. Wills, B. Johanson, and O. Eriksson, Phys. Rev. Lett. 75, 1602 (1995). 